\title{
PT3a Stage Finding
}

National Cancer Institute

\section{Source}

National Cancer Institute. pT3a Stage Finding. NCI Thesaurus. Code C48769.

A pathologic primary tumor TNM stage finding. The definition of pT 3a stage finding depends on the particular type of cancer that it refers to; for example, for cervical cancer, PT 3a stage finding is defined as follows: cancer involves lower third of vagina, without extension to pelvic wall; for kidney cancer, pT3a stage finding is defined as follows: cancer with tumor grossly extending into the renal vein or its segmental (muscle containing) branches or tumor invading perirenal and/or renal sinus fat but not beyond Gerota's fascia. (from AJCC 7th Ed.) 